\title{
HIV Screening in the Emergency Department: Where Do We Stand?
}

Michael Heller*

Director of Clinical Research, Icahn School of Medicine at Mount Sinai, Emergency Medicine, United States

\begin{abstract}
Recent data from the USA and elsewhere indicating that the number of new HIV/ AIDS cases continues to rise has stimulated state and national efforts to identify patients with undetected HIV infection. Although the use of Emergency Departments (EDs) as a venue for screening remains controversial, the ED has become a major focus of this effort with more than a dozen studies of ED screening for HIV reported in recent years. This review of ED studies published since 2005 summarizes these findings: selection bias in these programs appears common, acceptance of testing varies widely, positivity rates are usually less than $1 \%$ and the cost per case found is approximated to be between $\$ 1600$ to $\$ 10,000$.
\end{abstract}

Keywords: HIV; Screening; AIDS; Emergency department

\section{Objective}

The use of the Emergency Department (ED) as a venue for screeing conditions as diverse as domestic abuse and childhood vaccination has increased markedly in recent decades despite concerns that mass screening is an inefficient use of Emergency resources. ED screening for HIV has also grown sharply in the past decade and is now mandated in several jurisictions. In New York State, for example, a law was enacted in September 2010 requiring that HIV testing must be offered to anyone between the ages of 13-64 receiving hospital or primary care services, including in the ED. But the cost and effectiveness of such a broad (and unfunded) mandate have rarely been addressed. Our purpose was to review the recent published literature on HIV screening in the ED to determine if the yield and costs of such programmes justify their existence and expansion.

\section{Background}

There is little dispute that increased early HIV detection is an important goal with significant public health consequences. It has been estimated that are approximately 40,000 new HIV cases per year in the United States; of these new cases $40 \%$ will develop AIDS in less than a year [1]. The most recent Centers of Disease Control (CDC) data reported an increased incidence of approximately 56,300 people that were newly infected with HIV in 2006 [2]. Over half (53\%) of these new infections occurred in homosexual and bisexual men [2].

In the early 1990s, perhaps as a result of a national HIV awareness program, the number of new HIV cases decreased. However, this trend ended by 1999-2004 as new HIV cases continued at steady rates [3]. In 1993, the CDC recommended routine HIV screening to the general medical community for those at high risk and in populations where HIV prevalence was greater than $1 \%$. This has been called "the most widely ignored recommendation the CDC has ever made" [1]. Recognizing that its efforts had stalled, in 2003 the CDC announced a new initiative "Advancing HIV Prevention: New Strategies for a Changing Epidemic", which was aimed at reducing barriers to early diagnosis and increasing access to medical care for those with HIV [4]. The ultimate goal was to make HIV testing a routine part of medical care. Then in 2006, the CDC announced its broadest recommendation in HIV testing yet: routine HIV testing for patients in all health care settings unless the patient declines or opts-out [3]. HIV infected patients are frequent users of Emergency Departments the CDC and some state legislatures have recognized the need to include EDs in the routine screening of HIV [4-6].

\section{Methods}

We conducted a literature search on HIV Testing in the ED from 2005 to 2012, searching MEDLINE for the following keywords: "HIV Screening," "HIV Testing," "emergency department," "emergency room," "outpatient," and "urgent care." We supplemented the MEDLINE search with a manual search of related references from the emergency medicine literature using the online search engine Google Scholar and accessing references which did not appear in our computerized search but were referenced in published articles that did. For each screening program identified we attempted to determine the number of patients approached for screening, the percentage of patients who accepted testing, the percentage found positive and the cost per new patient identified. The study was granted an exemption from IRB review at our institution (Table 1).

\section{Results}

Table 1 is a summary of the results of HIV screening in domestic EDs published from 2005 through 2011.

Costs in ED HIV screening studies have been reported as low as $\$ 1,638$ and as high as $\$ 9,116$ per case of HIV identified [5-7]. It was often unclear how many of these cases were truly new cases identified and even less clear if effective treatment and disease-prevention strategies were employed in all cases. Actual costs of the programs were often impossible to evaluate, especially in those cases where preexisting ED personnel were utilized for screening and no additional salary costs were enumerated although the time required to perform the screening for the thousands of patients involved represents a true cost to the system.

Collective spending for all HIV testing and counseling in the United States in 2007 was approximated at $\$ 152.1$ million or $26 \%$ of the collective HIV prevention budget [8]. At the end of 2010, the CDC

${ }^{*}$ Corresponding author: Michael Heller, Director of Clinical Research Icahn Schoo of Medicine at Mount Sinai, Emergency Medicine, 16 St. and First Ave New York, New York 10003, United States, Tel: 610 2162919; E-mail: mheller@chpnet.org

Received February 06, 2016; Accepted March 23, 2016; Published March 31, 2016

Citation: Heller M (2016) HIV Screening in the Emergency Department: Where Do We Stand? Health Care: Current Reviews 4: 162. doi: 10.4172/2375-4273.1000162

Copyright: (C) 2016 Heller M. This is an open-access article distributed under the terms of the Creative Commons Attribution License, which permits unrestricted use, distribution, and reproduction in any medium, provided the original author and source are credited. 


\begin{tabular}{|c|c|c|c|c|c|}
\hline Location (reference) & Year & Age & $\%$ accepting testing & \# tested & New HIV (\%) \\
\hline New York (4) & $05-06$ & $>18$ & $98 \%$ & 1,709 & $13(0.8 \%)$ \\
\hline New York (19) & $06-07$ & $>13$ & $28 \%$ & 2,563 & $24(0.9 \%)$ \\
\hline Boston (11) & $03-04$ & $22-54$ & $45 \%$ & 970 & $7(0.7 \%)$ \\
\hline Boston (11) & $03-04$ & $15-21$ & $61 \%$ & 464 & $1(0.2 \%)$ \\
\hline Boston (20) & 07 & $>18$ & $61 \%$ & 854 & $5(0.6 \%)$ \\
\hline Washington DC (6) & 06 & $13-64$ & $60 \%$ & 2,476 & $26(1.1 \%)$ \\
\hline Atlanta (21) & $08-10$ & $>18$ & $85 \%$ & 7,616 & $13(1.7 \%)$ \\
\hline Augusta (22) & $08-09$ & $13-64$ & $91 \%$ & 8,504 & $34(0.4 \%)$ \\
\hline Cincinnati (24) & $03-07$ & $\mathrm{~N} / \mathrm{A}$ & $62 \%$ & 8,450 & $77(0.9 \%)$ \\
\hline Chicago (4) & $03-04$ & $15-54$ & $48 \%$ & 1,447 & $8(0.6 \%)$ \\
\hline Denver (18) & $07-09$ & $>16$ & $25 \%$ & 6,933 & $15(0.2 \%)$ \\
\hline Houston () & $08-09$ & $>18$ & $99.7 \%$ & 14,093 & $80(0.6 \%)$ \\
\hline Oakland (4) & $05-06$ & $>12$ & $53 \%$ & 6,368 & $65(1.0 \%)$ \\
\hline Oakland (14) & $05-06$ & $>12$ & $48 \%$ & 7,923 & $55(0.7 \%)$ \\
\hline Oakland (23) & $07-08$ & $>15$ & $23 \%$ & 4,675 & $21(0.45 \%)$ \\
\hline Oakland (23) & $07-08$ & $>15$ & $63 \%$ & 4,053 & $(0.2 \%)$ \\
\hline Los Angelas (4) & $05-06$ & $>18$ & $84 \%$ & 1,288 & $19(1.5 \%)$ \\
\hline
\end{tabular}

Table 1: Characteristics Of Published Studies Of Emergency Department-Based Hiv Screening Published Since 2005.

anticipated an additional $\$ 142.5$ million in funding for an additional expanded testing initiative [8]. During an initial expanded testing initiative from 2007 to 2009, more than 1.4 million HIV tests were performed with more tests conducted in EDs than in any other clinical venue [8].

\section{Patient acceptance of HIV screening in the ED}

One of the concerns about implementation of broad-based mandatory HIV ED screening programs is patient acceptance. A potential roadblock to widespread acceptance is the need for specific consent. In 2003, the CDC recommended a significant change in the process of obtaining consent for HIV testing, advocating that consent for HIV testing can be implied with consent for general health care. The American Academy of HIV Medicine voiced concern that implied consent without the previously required pretest counseling might result in failure to offer an opt-out option [1]. The public, however, has supported broad ED HIV screening. In a 2006 survey of 1,519 ED patients, 91\% said they would recommend ED HIV testing to a friend and $77 \%$ either agreed or strongly agreed that the ED was a good place for ED HIV testing. Similar acceptance was found in another study [8].

Acceptance rates for ED HIV screening vary widely as well, from $23 \%$ to $98 \%$ [4-14]. One factor in the variation may be who actually offers the HIV testing. HIV screening may be offered by an HIV counselor who also takes the time to also give pretest counseling, a busy ED triage nurse, an ED physician or even a video with pretest and posttest information [15]. ED patients were found to be more likely to accept HIV screening if it was recommended by an ED physician [9]. Perhaps most importantly, although ED screening for HIV implies a nonselective process, this is unlikely to be true in practice as is evident from the widely varying rates of patient acceptance (from less than one quarter to almost $100 \%)$ and positivity (.2\% to $1.7 \%)$. Our own experience (with more than 12,000 ED-screened patients by a dedicated HIV counselor) found a positivity rate of .6\% and a cost of $\$ 10,434$ per case identified. Our mean age of patients screened was 28 , fully 18 years younger than the mean age of ED patients in our department, again evidence that screening was neither random nor non-selective.

\section{Discussion}

Whether the ED is the most suitable venue for ED screening is a societal judgement that cannot be fully answered by empirical studies such as ours. But several factors regarding ED screening programs may be answered by the last decade's experience. First, a positivity rate of less than $1 \%$ is to be expected unless the "screening" is highly targeted. Acceptance rates will vary dramatically depending on how targeted the screening is and whether or not it is proferred by the physician rather than other health care provider. Finally, costs can be expected to be between $\$ 2000$ and $\$ 10,000$ for each case identified.

\section{Conclusion}

ED screening for HIV is an established and growing practice, at least in the United States. It has already been mandated in some juristicions and it is likely to be considered routine practice in many more within the next few years. The number of new HIV cases found is modest, however, and the costs significant.

There are likely multiple reasons why it has been difficult to decrease HIV prevalence. The approximately $25 \%$ of those living with HIV unknowingly are unaware that they are at risk of spreading it to others. $\mathrm{HIV}$ is also increasing in nontraditional risk groups without traditional risk factors [13]. It has been found that nontraditional risk groups are more likely to decline routine HIV testing, mainly because they feel they are not at risk [16]. Another barrier to broad HIV testing has been the Informed Consent process that required pretest counseling prior to testing. This barrier was removed as part of the 2003 CDC testing recommendations.

To decrease HIV prevalence HIV-infected patients who are undiagnosed and capable of transmitting HIV unknowingly must be identified. Although screening of HIV in ED patients has identified some undiagnosed HIV infected patients, the pecentage identified appears low and the costs are significant, particularly in an era of limited resources [5]. One study group states "nontargeted opt out rapid HIV screening in conjunction with diagnostic testing was associated with approximately 30 times the number of rapid HIV tests performed, yet only a few more patients were newly identified with HIV infection when compared to diagnostic testing alone" [17]. Targeted testing, previously the only testing strategy, has been shown to increase the rate of newly diagnosed HIV infections by two to three times over nontargeted testing at a much lower cost [16]. Targeted testing is defined as performing an 
Citation: Heller M (2016) HIV Screening in the Emergency Department: Where Do We Stand? Health Care: Current Reviews 4: 162. doi: 10.4172/23754273.1000162

HIV test for subpopulations of persons at higher risk, typically defined on the basis of clinical, behavior, or demographic characteristics [3].

A recent cost-analysis, including a jail population, confirmed that the costs of non-targeted screening were "within the range of that reported in the literature" [18]. A strategy of targeted (rather than universal) screening might increase the percentage of newly diagnosed HIV-infected patients diagnosed in the ED, increasing costeffectiveness even at the expense of decreasing the absolute number of patients detected. Such studies from an ED population would appear to be a reasonable area for future research.

\section{References}

1. McKenna M (2007) HIV testing: should the emergency department take part? Ann Emerg Med 49: 190-192.

2. Centers for Disease Control and Prevention (CDC) (2008) MMWR Morb Mortal Wkly Rep. HIV prevelance estimates- US, 2006 57: 1073-1076.

3. Hall HI, Song R, Rhodes P, Prejean J, An Q, et al. (2008) Estimation of HIV incidence in the United States. JAMA 300: 520-529.

4. Centers for Disease Control and Prevention (CDC) (2007) Rapid HIV testing in emergency departments--three U.S. sites, January 2005-March 2006. MMWR Morb Mortal Wkly Rep 56: 597-601.

5. Silva A, Glick NR, Lyss SB, Hutchinson AB, Gift TL, et al. (2007) Implementing an HIV and sexually transmitted disease screening program in an emergency department. Ann Emerg Med 49: 564-572.

6. Brown J, Shesser R, Simon G, Bahn M, Czarnogorski M, et al. (2007) Routine HIV screening in the emergency department using the new US Centers for Disease Control and Prevention Guidelines: results from a high-prevalence area. J Acquir Immune Defic Syndr 46: 395-401.

7. Farnham PG, Hutchinson AB, Sansom SL, Branson BM (2008) Comparing the costs of HIV screening strategies and technologies in health-care settings. Public Health Rep 123 Suppl 3: 51-62.

8. Jeng K, Rothman RE (2011) Update on Emerging Infections: news from the
Centers for Disease Control and Prevention. Commentary. Ann Emerg Med 57: 298-300

9. Haukoos JS, Hopkins E, Byyny RL; Denver Emergency Department HIV Testing Study Group (2008) Patient acceptance of rapid HIV testing practices in an urban emergency department: assessment of the 2006 CDC recommendations for HIV screening in health care settings. Ann Emerg Med 51: 303-309, 309.

10. Merchant RC, Catanzaro BM (2009) HIV testing in US EDs, 1993-2004. Am J Emerg Med 27: 868-874.

11. Mehta SD, Hall J, Lyss SB (2007) Adult and pediatric emergency department sexually transmitted disease and HIV screening: programmatic overview and outcomes. Acad Emerg Med 14: 250-258.

12. Lyons MS, Lindsell CJ, Raab DL, Ruffner AH, Trott AT, et al. (2009) Comparison of emergency department HIV testing data with visit or patient as the unit of analysis. J Med Screen 16: 29-32.

13. Merchant RC, Seage GR, Mayer KH, Clark MA, DeGruttola VG, et al. (2008) Emergency department patient acceptance of opt-in, universal, rapid HIV screening. Public Health Rep 123 Suppl 3: 27-40.

14. White DA, Scribner AN, Schulden JD, Branson BM, Heffelfinger JD (2009) Results of a rapid HIV screening and diagnostic testing program in an urban emergency department. Ann Emerg Med 54: 56-64.

15. Calderon Y, Leider J, Hailpern S, Chin R, Ghosh R, et al. (2009) High-volume rapid HIV testing in an urban emergency department. AIDS Patient Care STDS 23: $749-755$

16. Haukoos JS, Hopkins E, Eliopoulos VT, Byyny RL, Laperriere KA, et al (2007) Development and implementation of a model to improve identification of patients infected with HIV using diagnostic rapid testing in the emergency department. Acad Emerg Med 14: 1149-1157.

17. Haukoos JS, Hopkins E, Conroy AA, Silverman M, Byyny RL, et al. (2010) Routine opt-out rapid HIV screening and detection of HIV infection in emergency department patients. JAMA 304: 284-292.

18. Spaulding AC, MacGowan RJ, Copeland B, Shrestha RK, Bowden CJ, et al. (2015) Costs of Rapid HIV Screening in an Urban Emergency Department and a Nearby County Jail in the Southeastern United States. PLoS One 10 e0128408. 